\title{
Factors affecting treatment practices of patent medicine vendors for malaria in un- der-five children: implications for malaria control in Nigeria
}

\author{
Chukwuemeka A. Ihesie, Ofonime E. Johnson, Olugbemi O. Motilewa and Queen M. Umoren \\ Ghana Med J 2019; 53(3): 237-247 doi: http://dx.doi.org/10.4314/gmj.v53i3.8
}

\author{
University of Uyo Teaching Hospital, Uyo, Akwa Ibom State, Nigeria
}

Corresponding author: Chukwuemeka A. Ihesie

E-mail: austinihesie@yahoo.com

Conflict of interest: None declared

\begin{abstract}
SUMMARY
Background: Patent medicine vendors (PMVs) are the most common source of antimalarial drugs and treatment for majority of Nigerians. The quality of their practice could have implications for malaria control. This study sought to explore the factors influencing the malaria treatment practices of PMVs for under-five children in Akwa Ibom State. Methods: A cross-sectional survey using an interviewer-administered questionnaire was conducted among 176 PMVs selected by simple random sampling from two local government areas (LGAs). In addition, four focus group discussions (FGD) were conducted to generate qualitative data. Quantitative data was analysed using SPSS version 20 while content analysis was done on the qualitative data.

Results: Artemisinin Combination Therapy (ACT) was the most frequently recommended antimalarial treatment by PMVs (75.6\%) for children as against chloroquine (17\%) and Sulphadoxine/Pyrimethamine (2.8\%). However, only $39.2 \%$ of PMVs recommended the appropriate antimalarial treatment (ACTs at the right dose for age), while $71 \%$ recommended referral for severe malaria.

Factors found to be associated with appropriate management of malaria from quantitative analysis included Educational qualification, attending malaria training and their knowledge of malaria. The FGDs showed that severity of child's illness, parents/caregivers drug request and perceived ability of the parents/caregiver to afford the drugs influenced PMVs malaria treatment practices.

Conclusion: Knowledge of malaria, severity of child's illness and parents' drug request influenced the treatment practices of PMVs. Training PMVs on appropriate malaria management and community health education/sensitization to leverage on the influence of client-demand on ACT use is recommended to improve PMVs treatment practice.
\end{abstract}

Keywords: Malaria, under-five children, patent medicine vendors, ACT, Nigeria

Funding: This study was conducted using mainly personal funds of the lead author with some support from the University of Uyo Teaching Hospital.

\section{INTRODUCTION}

Malaria remains a major public health problem worldwide, being responsible for an estimated 216 million cases of illness and 445,000 deaths in 2016, of which more than $80 \%$ were in the African region. ${ }^{1}$ Majority of global malaria deaths occurred in children under five years of age. ${ }^{1}$ In Nigeria, malaria accounts for $60 \%$ of outpatients visits and $30 \%$ of hospitalizations among under-five children. Malaria is one of the commonest causes of childhood mortality in the country and Nigeria along with 2 other countries (Congo DR and India) account for $40 \%$ of the global malaria deaths. ${ }^{2}$ Prompt access to early diagnosis and effective antimalarial treatment have been identified as major strategies for reducing the morbidity and mortality attributable to malaria especially in children under-five years. ${ }^{3}$
The World Health Organization (WHO) recommends the use of Artemisinine-based Combination Therapy (ACT) as first line treatment for uncomplicated malaria. ${ }^{3}$ This followed the onset of chloroquine-resistant malaria and the increasing parasite resistance to sulphadoxine-pyrimethamine (SP) which resulted in the worsening of morbidity and mortality especially in children. ${ }^{4}$ Artemisinine-based Combination Therapy was adopted in 2005 in Nigeria as the recommended treatment for uncomplicated malaria in line with the position of WHO and following country-wide drug efficacy trials in 2002 and 2004 which showed chloroquine and sulphadoxine-pyrimethamine resistance by malaria parasites. ${ }^{5}$ 
The National Malaria Elimination Programme which coordinates malaria control activities in Nigeria considers access to affordable quality assured anti-malarial, integrated community case management and involvement of the private sector especially patent medicine vendors (PMVs) as some of its key strategies for effective malaria case management. ${ }^{2}$

This is due to evidence showing that although many households in Nigeria seek treatment for malaria from a variety of formal and informal sources, a vast majority, especially the poor in both rural and urban areas treat malaria in adults and children through self-medication with anti-malarials obtained from Patent Medicine Vendors (PMVs). ${ }^{6,7}$ With almost 40,000 registered members in the country and a significantly large number of unregistered operators, PMVs provide a huge potential of informal care providers who can be enlisted in malaria control activities with adequate training and capacity building. ${ }^{2}$

The PMV is described as someone who is licensed to sell proprietary and over-the-counter (OTC) drugs commercially as a retail business venture but has no formal pharmacy training. The Pharmacy Law of Nigeria licenses PMVs to sell only pre-packaged patent medicines. The law requires that the licensee should be at least 21 years of age and should submit two referees but is silent on minimum educational qualification..$^{8,9}$

Inspite of the limitation of their scope of operations by law to only OTC drugs, most PMVs in Nigeria sell all types of drugs based on demands of their customers and profits. The proximity of PMVs to their clients in the community make them a major source of advice and medication to the people on health issues including malaria and most of their clients perceive them as very knowledgeable., ${ }^{9}, 10$

Patent medicine vendors (PMVs) are highly patronized and have assumed a crucial role as primary healthcare providers for treatment of malaria in many communities. It is therefore recognized that PMVs could play an important role in the scaling up of coverage of appropriate malaria treatment including ACTs. However, the quality of their practices can have implications for malaria control. Previous studies have identified PMVs as having poor knowledge on malaria, stocking and selling inappropriate antimalarial medication including artemisinine monotherapy and at sub-optimal dosages, practicing polypharmacy and relying on caregivers' diagnosis in dispensing drugs without asking questions. ${ }^{11-13}$ This study intends to explore the malaria treatment practices of PMVs for under-five children and identify the factors influencing them in Akwa Ibom State.

\section{METHODS}

\section{Study Location}

The study was conducted in Abak and Ikot Ekpene Local Government Areas (LGAs) of Akwa Ibom State located in the coastal South-eastern area of Nigeria. The state has 31 LGAs and experiences climatic conditions which encourage perennial malaria transmission due to abundant rainfall with very high temperatures all year round. ${ }^{14,15}$ Abak LGA lies on the South West part of Akwa Ibom State and has a projected population of 192,690 (based on the 2006 National Population Census). The LGA is served by 2 secondary and 10 primary health facilities.

Ikot Ekpene LGA lies on the North-Western flank of Akwa Ibom State, with a projected population of 179,704 (based on the 2006 National Population Census). It is served by 3 secondary and 14 primary health facilities. In both LGAs, the informal health services are provided by PMV shops, faith-based healing houses, alternative care and herbal practitioners. The main languages spoken are English and Annang. Christianity is the predominant religion of the people.

\section{Study population}

The study population was all PMVs registered with the Abak and Ikot Ekpene LGA chapter of the National Association of Proprietary and Patent Medicine Vendors (NAPPMED) in Akwa Ibom State. PMVs are a common feature on the streets of both study LGAs. In terms of distribution, they tend to be more concentrated around busy streets and near the markets.

All patent medicine shops operating within an LGA are expected to register with the LGA branch of NAPPMED as well as the Pharmaceutical Council of Nigeria (PCN). They are also required to renew their registration annually with the PCN for a fee. There were 174 and 213 PMVs registered with the NAPPMED in Abak and Ikot Ekpene LGAs respectively at the time of the study and these constituted the sampling frame.

\section{Inclusion Criteria}

All patent medicine vendors registered with their association (NAPPMED) in Abak and Ikot Ekpene LGAs.

\section{Exclusion Criteria}

General shops selling some drugs alongside general goods, and Itinerant drug hawkers

\section{Study design}

This was a cross-sectional survey conducted as part of an interventional study among a sample of 176 PMVs equally distributed among the 2 LGAs. The sample size for the study was derived from a formula for comparison of two proportions. ${ }^{16}$ A sample size of 88 for each LGA was computed. 


\section{Sampling methodology}

The two LGAs for the study were chosen by simple random sampling. All 31 LGAs of Akwa Ibom State were arranged in alphabetical order and then represented by numbers. Abak and Ikot Ekpene LGAs were then chosen using simple random sampling by balloting from all the LGAs in the State. Simple random sampling was also used to select 88 PMVs from each of the study LGAs. The list of registered PMVs in each LGA was used as the sampling frame. Sampling method for qualitative data focus group discussion (FGD) was purposive and consisted of 24 persons.

\section{Data Collection}

The data for this study was collected in August 2013. An interviewer administered questionnaire was administered to all study participants. In addition, four focus group discussions (FGD) were used to generate qualitative data using a FGD guide which covered the scope of their perception and treatment practices as well as identifying the factors that influenced or determined the treatment practices of PMVs.

\section{Data Analysis}

Questionnaires were manually sorted out and then coded before entry into the computer. Data was analyzed using IBM SPSS software, version 20 for Windows. Data analysis was done using descriptive statistics and inferential statistics with level of significance set at 5\%.

The data from the FGDs were transcribed verbatim from the audio record and content (thematic) analysis done. The transcriptions were organized under thematic headings and later developed into an ethnographic summary with illustrative quotes capturing the different ranges of opinions, perception and stated practices.

\section{Definition of Main Outcome measures}

A) Knowledge of Malaria (Cause, symptoms and signs, prevention and treatment/policy).

This was based on the sum total of their responses to questions on knowledge of malaria (covering cause and transmission, symptoms and signs, prevention and treatment/policy) in the questionnaire. The maximum total knowledge score attainable was 54 . The scores were converted to percentages and categorized as:

$<50 \%$ as Poor knowledge, $50-74 \%$ as Good knowledge and

$\geq 75 \%$ as Very good knowledge

\section{B) Appropriate anti-malarial treatment for simple uncomplicated malaria.}

This was defined as the administration of the recommended ACT (AL or AA) to children under five years in the right dose, frequency and duration as described below based on the National Policy on Malaria diagnosis and treatment as listed below. ${ }^{5}$

Arthemeter Lumenfantrine (AL) for children 3years and below at 1 tablet (20mg arthemeter $+120 \mathrm{mg}$ lumenfantrine) twice daily for 3 days and for children $4-5 y e a r s, 2$ tablets twice daily for 3 days;

Artesunate Amodiaquine (AA) for children 3years and below: 1 tablet $(25 / 67.5 \mathrm{mg}$ ) daily for 3 days; for children 4-5years, 1 tablet $(50 \mathrm{mg} / 135 \mathrm{mg})$ daily for 3 days.

The PMVs were categorized based on their responses into those giving appropriate anti-malarial treatment and those giving inappropriate anti-malarial treatment.

\section{C) Prompt referral practice}

This is the immediate (as soon as they are assessed) referral of children under 5yrs with any sign or symptom of severe malaria to the nearest health facility. The referral practice of PMVs was categorised as "Refer - Good" or "Intensified treatment -Poor" based on their response to the questionnaire.

\section{Ethical considerations}

Before the commencement of the study, ethical clearance was sought and obtained from the Ethics and Research Committee of the University of Uyo Teaching Hospital, Uyo (UUTH/AD/S/96/VOL.XII/53) and the Akwa Ibom State Ministry of Health (MH/PRS/99/VOL.IV/128). Permission to carry out the study was also sought from the Local Government chapters of NAPPMED while informed consent was obtained from participants.

\section{RESULTS}

\section{Socio-demographic Data}

Respondents had an average age of 31.27 years with majority (55.1\%) of them aged between 20 and 29 years (Table 1).

Table 1 Socio-demographic and business characteristics of respondents $($ Total $=176)$

\begin{tabular}{|c|c|}
\hline Variables & $\mathrm{n}(\%)$ \\
\hline \multicolumn{2}{|l|}{ Age group (years) } \\
\hline $20-29$ & $97(55.1)$ \\
\hline $30-39$ & $52(29.5)$ \\
\hline $40-49$ & $13(7.4)$ \\
\hline$\geq 50$ & $14(8.0)$ \\
\hline Mean age $( \pm S D)$ & $31.27( \pm 8.91)$ \\
\hline \multicolumn{2}{|l|}{$\operatorname{Sex}$} \\
\hline Male & $103(58.5)$ \\
\hline Female & 73 (41.5) \\
\hline \multicolumn{2}{|l|}{ Marital status } \\
\hline Single & $80(45.5)$ \\
\hline Married & $96(54.5)$ \\
\hline \multicolumn{2}{|l|}{ Highest educational level } \\
\hline Tertiary & $36(20.5)$ \\
\hline Secondary & $138(78.4)$ \\
\hline
\end{tabular}




\section{Original Article}

\begin{tabular}{|c|c|}
\hline Variables & n (\%) \\
\hline Primary & $2(1.1)$ \\
\hline \multicolumn{2}{|l|}{ Duration in business (years) } \\
\hline$\leq 5$ & $107(60.8)$ \\
\hline $6-10$ & $41(23.3)$ \\
\hline $11-15$ & $15(8.5)$ \\
\hline$>15$ & $13(7.4)$ \\
\hline Mean age $( \pm S D)$ & $6.27( \pm 6.17)$ \\
\hline \multicolumn{2}{|l|}{$\begin{array}{l}\text { Shop visited by regulatory au- } \\
\text { thority }\end{array}$} \\
\hline Yes & $109(61.9)$ \\
\hline No & $67(38.1)$ \\
\hline
\end{tabular}

All respondents were Christians and predominantly male $(58.5 \%)$. The average number of years in business of the respondents was 6.27 years and $43.2 \%$ (76) of the respondents had ever attended training on malaria.

\section{Knowledge of PMVs on Malaria}

Majority of the PMVs (74.4\%) had an overall good knowledge of malaria while $19.9 \%$ of them had a poor knowledge and $5.7 \%$ had a very good knowledge. The mean knowledge score of the PMVs was 32.1 out of 54.

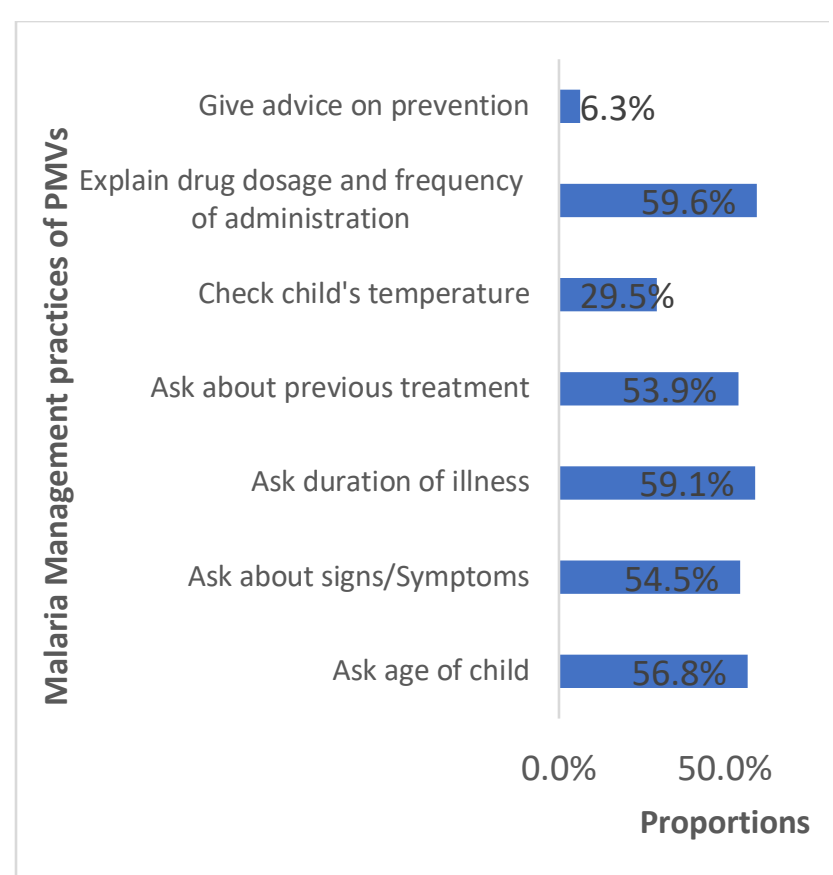

Figure 1: Management practices of PMVs for Childhood Malaria

\section{Malaria Treatment Practices}

Five of the seven malaria management steps assessed were practiced by more than half of the PMVs with explaining antimalarial drug dosage and frequency of administration (59.6\%) and asking about duration of illness in the child (59.1\%) being the 2 commonest management steps.
Giving advice on malaria prevention (6.3\%) and checking the child's temperature $(29.5 \%)$ were the least common management steps (Figure 1).

The antimalarial drugs for children stocked by PMVs include ACT (96\%), Arthermeter (38.1\%), Chloroquine (86.9\%) and Sulphadoxine/Pyrimethamine (97\%). Among these, ACT was the most frequently recommended antimalarial treatment by PMVs $(75.6 \%)$ for children as against chloroquine (17\%) and Sulphadoxine/Pyrimethamine (2.8\%) (Figure 2).

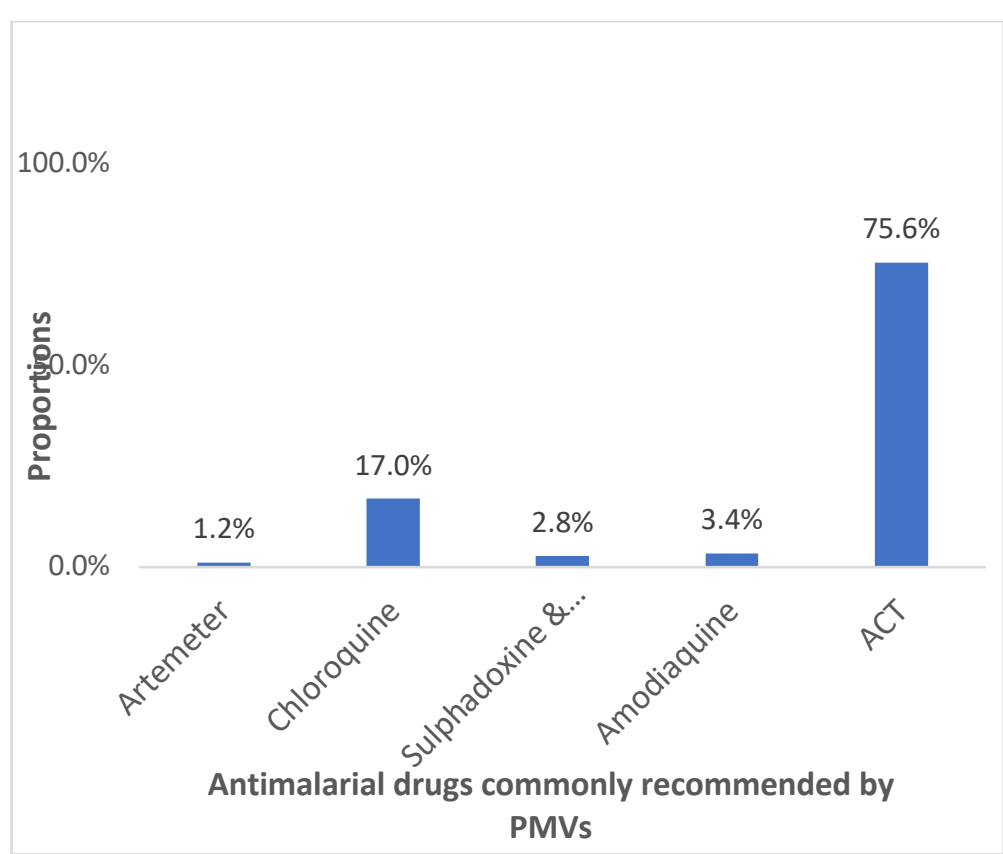

Figure 2 Antimalarial drug commonly recommended by PMVs for treatment of simple malaria in under-five children

Only $39.2 \%$ (69) of the PMVs recommended the appropriate antimalarial treatment ACTs at the right dose for age. Qualitative data on malaria treatment practice from the FGD shows that more than half (13) of the participants mentioned that they use ACTs like AL and AA.

Most of the remaining PMVs said they treat malaria in children by using either CQ syrup or SP and antipyretics like PCM. When probed on why they use CQ instead of $\mathrm{ACT}$, one of the male PMVs said that "sometimes the ACT medicine dem dey too strong for some children" referring to some of the side-effects of ACT drugs.

Another PMV stated his preference for CQ as based on experience that it works better than ACTs. A few other PMVs indicated their preference for injections as well as the use of antibiotics. 
One male PMV said he would give the child septrin in addition to the CQ while a female respondent said she would "check the temperature and if the baby is hot I will sponge him then give him c-pen (crystalline penicillin) injection". Another said she prefers injections because "it works faster". Artesunate monotherapy use also featured in the responses by 3 respondents. The use of enema as an adjunct therapy was mentioned by one female respondent. According to her, "sometimes I give the child enema to clear his system before I treat him with ACT".

When probed on their knowledge of the national policy on malaria treatment, most of the participants mentioned that they were aware that government is recommending the use of ACT for the treatment of malaria. However, some were unaware that CQ use had been discouraged while all of the PMVs were unaware of the treatment policy discouraging the use of artesunate monotherapy.

A number of reasons were given by some PMVs for the continued use of CQ and other non-ACT antimalarials for treatment in spite of the government policy advocating ACT use. Some identified the rapid action of CQ as the reason. One PMV said "CQ calms down the body quickly" while another said "CQ injections quickly calm down the fever, Injection is more powerful than tablets".

Another PMV was of the opinion that the ACT drugs were too strong for children, according to him "the pikin body no fit take the medicine, the medicine (ACT) dey too strong". Affordability also featured as a reason for the continued use of non-ACT antimalarials. One PMV said "SP is used because it is cheaper and more affordable for the parents, it is N50 while ACT (Lumartem) is N150 to N200".

\section{Referral practices}

$71 \%$ (125) of PMVs reported they would immediately refer a child with severe malaria. $16.5 \%$ had heard of prereferral treatment with rectal artesunate but only 1\% (2) PMVs had rectal artesunate in stock and only 1 PMV reported ever using it.

This however was different from the findings of the FGDs on severe malaria where only 2 respondents said they would refer immediately to the hospital. Some of the others said they would administer some form of treatment before they refer. According to a male PMV he would "Pour water, give glucose and refer" when probed about the choice of glucose he said to help revive the strength of the weak child. Another said he would "Pour am (the child) water, give PCM, Folic Acid and B.co (vitamin B complex) then refer".

For those that referred, most said their decision to refer was based on the severity of illness and failure of the child to respond to treatment after 3 days. Some other PMVs opined that they would treat the child with more medications rather than refer. One of them said she would "tepid sponge then give analgin injection, c-pen and paraldehyde combined" while another said she would "check for pallor, give blood builders like astymin then give antimalarial like La tesen". One male respondent said he would "find out what has been given and treat again" while another said he would send the child to a laboratory for test.

When probed about the use of rectal artesunate for prereferral treatment only 2 PMVs had heard about it but neither stocked nor used it. According to one of them "it is not a popular or common medicine in the market and e no dey easy to find". The other person said he had not bothered trying to get it.

\section{Factors associated with malaria treatment practice among PMVs}

Quantitative analysis showed that a number of factors including educational qualification of PMVs, previous attendance of a malaria training, shop visit by a regulatory authority and their knowledge of malaria had statistically significant association with appropriate treatment of malaria in under-five children by PMVs in the study. However, only previous attendance of a malaria training was significantly associated with likelihood to refer a child with severe malaria by respondents $(p=0.007)$. Other socio-demographic and business indicator variables did not show any significant association with action taken by respondents for severe malaria in under-five children (Table 2 and Table 3 ). 
Table 2 Association between socio-demographic/business indicator variables and appropriate antimalarial treatment by PMVs

VARIABLE

Age Group (years)
$20-29$
$30-39$
$40-49$
$\geq 50$
Sex
Male
female
Marital Status
Single
Married

Educational qualification
Tertiary
Secondary
Primary
Duration in business (years)
$\leq 5$ years
$6-10$ years
$11-15$ years
$\geq 16$ years
Ever attended malaria training
Yes
No
Shop ever visited by regulatory
authority
Yes
No
Total knowledge of malaria
Poor
Good
Very good
$\mathrm{p}<0.05$

\begin{tabular}{|c|c|c|c|c|}
\hline \multicolumn{3}{|c|}{ Drug treatment practice } & \multirow{2}{*}{$\begin{array}{l}\text { TOTAL } \\
\mathrm{N}=176 \\
\mathrm{n}(\%)\end{array}$} & \multirow{2}{*}{$\begin{array}{l}\text { STATISTICAL } \\
\text { INDICES } \\
\left(\chi^{2} ; \text { Df; p-value }\right)\end{array}$} \\
\hline $\begin{array}{l}\text { Appropriate } N=69 \\
(\%)\end{array}$ & n & $\begin{array}{l}\text { Inappropriate } \\
\mathrm{N}=107 \quad \text { n (\%) }\end{array}$ & & \\
\hline $33(34.0)$ & & $64(66.0)$ & $97(55.1)$ & $\chi^{2}=3.884$ \\
\hline $25(48.1)$ & & $27(51.9)$ & $52(29.5)$ & $\mathrm{Df}=3$ \\
\hline $4(30.8)$ & & $9(69.2)$ & $13(7.4)$ & $\mathrm{p}=0.274$ \\
\hline $7(50.0)$ & & $7(50.0)$ & $14(8.0)$ & \\
\hline $42(40.8)$ & & $61(59.2)$ & $103(58.5)$ & $\chi^{2}=0.258$ \\
\hline \multirow[t]{2}{*}{$27(37.0)$} & & $46(63.0)$ & $73(41.5)$ & $\mathrm{Df}=1$ \\
\hline & & & & $\mathrm{p}=0.612$ \\
\hline $32(40.0)$ & & $48(60.0)$ & $80(45.5)$ & $\chi^{2}=0.039$ \\
\hline \multirow[t]{2}{*}{$37(38.5)$} & & $59(61.5)$ & $96(54.5)$ & $\mathrm{Df}=1$ \\
\hline & & & & $\mathrm{p}=0.844$ \\
\hline $21(58.3)$ & & $15(41.7)$ & $36(20.5)$ & Fisher's test \\
\hline $48(34.8)$ & & $90(65.2)$ & $138(78.4)$ & $\mathrm{Df}=2$ \\
\hline $0(0.0)$ & & $2(100)$ & $2(1.1)$ & $\mathrm{p}=0.013^{*}$ \\
\hline $39(36.4)$ & & $68(63.6)$ & $107(60.8)$ & $\chi^{2}=0.988$ \\
\hline $18(43.9)$ & & $23(56.1)$ & $41(23.3)$ & $\mathrm{Df}=3$ \\
\hline $6(40.0)$ & & $9(60.0)$ & $15(8.5)$ & $\mathrm{p}=0.804$ \\
\hline $6(46.2)$ & & $7(53.8)$ & $13(7.4)$ & \\
\hline $38(50.0)$ & & $38(50.0)$ & $76(43.2)$ & $\chi^{2}=6.540$ \\
\hline \multirow[t]{2}{*}{$31(31.0)$} & & $69(69.0)$ & $100(56.8)$ & $\mathrm{Df}=1$ \\
\hline & & & & $\mathrm{p}=0.011 *$ \\
\hline $51(46.8)$ & & $58(53.2)$ & 109 (61.9) & $\chi^{2}=6.910$ \\
\hline \multirow{2}{*}{$18(26.9)$} & & $49(73.1)$ & $67(38.1)$ & $\mathrm{Df}=1$ \\
\hline & & & & $\mathrm{p}=0.009^{*}$ \\
\hline $7(20.0)$ & & $28(80.0)$ & $35(19.9)$ & Fisher's test \\
\hline $56(42.7)$ & & $75(57.3)$ & $131(74.4)$ & $\mathrm{Df}=2$ \\
\hline $6(60.0)$ & & $4(40.0)$ & $10(5.7)$ & $\mathrm{p}=0.014^{*}$ \\
\hline
\end{tabular}

Table 3 Association between socio-demographic/business indicator variables and action taken for severe malaria by PMVs

\begin{tabular}{|c|c|c|c|c|}
\hline \multirow[t]{2}{*}{ VARIABLE } & \multicolumn{2}{|c|}{ Action taken for severe malaria } & \multirow{2}{*}{$\begin{array}{c}\text { TOTAL N }=176 \\
\mathrm{n}(\%)\end{array}$} & \multirow{2}{*}{$\begin{array}{c}\text { STATISTICAL } \\
\text { INDICES } \\
\left(\chi^{2} ; \text { Df; p-value }\right)\end{array}$} \\
\hline & $\mathrm{N}=125$ & $\begin{array}{l}\text { Intensify treatment } \\
\mathrm{N}=51 \quad \mathrm{n}(\%)\end{array}$ & & \\
\hline \multicolumn{5}{|l|}{ Age Group (years) } \\
\hline $20-29$ & $64(66.0)$ & $33(34.0)$ & $97(55.1)$ & Fisher's test \\
\hline $30-39$ & $40(76.9)$ & $12(23.1)$ & $52(29.5)$ & $\mathrm{Df}=3$ \\
\hline $40-49$ & $8(61.5)$ & $5(38.5)$ & $13(7.4)$ & $\mathrm{p}=0.107$ \\
\hline$\geq 50$ & $13(92.9)$ & $1(7.1)$ & $14(8.0)$ & \\
\hline \multicolumn{5}{|l|}{$\operatorname{Sex}$} \\
\hline Male & $77(74.8)$ & $26(25.2)$ & $103(58.5)$ & $\chi^{2}=1.683$ \\
\hline female & $48(65.8)$ & $25(34.2)$ & $73(41.5)$ & $\mathrm{Df}=1$ \\
\hline \multicolumn{5}{|l|}{ Marital Status } \\
\hline Single & $55(68.8)$ & $25(31.3)$ & $80(45.5)$ & $\chi^{2}=0.368$ \\
\hline Married & $70(72.9)$ & $26(27.1)$ & $96(54.5)$ & $\mathrm{Df}=1$ \\
\hline \multicolumn{5}{|l|}{ Educational qualification } \\
\hline Tertiary & $28(77.8)$ & $8(22.2)$ & $36(20.5)$ & Fisher's test \\
\hline Secondary & $96(69.6)$ & $42(30.4)$ & $138(78.4)$ & $\mathrm{Df}=2$ \\
\hline Primary & $1(50.0)$ & $1(50.0)$ & $2(1.1)$ & $\mathrm{p}=0.362$ \\
\hline$\leq 5$ years & $72(67.3)$ & $35(32.7)$ & $107(60.8)$ & Fisher's test \\
\hline
\end{tabular}




\section{Original Article}

\begin{tabular}{|c|c|c|c|c|}
\hline \multirow[t]{2}{*}{ VARIABLE } & \multicolumn{2}{|c|}{ Action taken for severe malaria } & \multirow{2}{*}{$\begin{array}{c}\text { TOTAL N }=176 \\
\mathrm{n}(\%)\end{array}$} & \multirow{2}{*}{$\begin{array}{l}\text { STATISTICAL } \\
\text { INDICES } \\
\left(\chi^{2} ; \text { Df; p-value }\right.\end{array}$} \\
\hline & $\mathrm{N}=125$ & $\begin{array}{l}\text { Intensify treatment } \\
N=51 \quad \text { n }(\%)\end{array}$ & & \\
\hline \multirow{3}{*}{$\begin{array}{l}6-10 \text { years } \\
11-15 \text { years } \\
\geq 16 \text { years }\end{array}$} & $29(70.7)$ & $12(29.3)$ & $41(23.3)$ & $\mathrm{Df}=3$ \\
\hline & $13(86.7)$ & $2(13.3)$ & $15(8.5)$ & $\mathrm{p}=0.342$ \\
\hline & $11(84.6)$ & $2(15.4)$ & $13(7.4)$ & \\
\hline \multicolumn{5}{|c|}{ Ever attended malaria training } \\
\hline Yes & $62(81.6)$ & $14(18.4)$ & $76(43.2)$ & $\chi^{2}=7.242$ \\
\hline No & $63(63.0)$ & $37(37.0)$ & $100(56.8)$ & $\mathrm{Df}=1$ \\
\hline \multicolumn{5}{|c|}{ Shop visited by regulatory authority } \\
\hline Yes & $77(70.6)$ & $32(29.4)$ & $109(61.9)$ & $\chi^{2}=0.020$ \\
\hline No & $48(71.6)$ & $19(28.4)$ & $67(38.1)$ & $\mathrm{Df}=1$ \\
\hline \multicolumn{5}{|l|}{ Total knowledge of malaria } \\
\hline Poor & $25(71.4)$ & $10(28.6)$ & $35(19.9)$ & Fisher's test \\
\hline Good & $90(68.7)$ & $41(31.3)$ & $131(74.4)$ & $\mathrm{Df}=2$ \\
\hline Very good & $10(100)$ & $0(0.0)$ & $10(5.7)$ & $\mathrm{p}=0.101$ \\
\hline
\end{tabular}

$* \mathrm{p}<0.05$

The FGDs exploring factors determining malaria treatment practices of PMVs for under-five children identified 2 main factors/themes illustrated in Table 4 below: child illness-related factors and parent-related factors.

Table 4 Themes identified for factors influencing PMV treatment of malaria

\begin{tabular}{|c|c|c|c|c|}
\hline$\sqrt{10}$ & FGD 1 & FGD 2 & FGD 3 & FGD 4 \\
\hline \multicolumn{5}{|c|}{$\begin{array}{l}\text { What are the factors that Influence how you treat uncomplicated malaria? } \\
\text { Themes elicited: }\end{array}$} \\
\hline $\begin{array}{l}\text { Information on symptoms of illness } \\
\text { and duration. }\end{array}$ & +++++ & ++++ & +++++ & +++ \\
\hline $\begin{array}{l}\text { Type of treatment given at home be- } \\
\text { fore coming to shop }\end{array}$ & + & - & - & - \\
\hline Findings from examination of child & + & + & ++ & + \\
\hline Type of drug requested by parents & +++ & +++ & ++ & +++ \\
\hline Ability of parents to afford drugs & + & ++ & & + \\
\hline
\end{tabular}

\section{Child Illness-Related Factors}

Many of the PMVs referred to the information and findings they get from the history and examination of the child as a determinant of how they will treat. Some said they would ask questions about duration of illness and appetite. One male PMV said, "I will observe the temperature, if it is too high I will use water on the body, I will also check the eyes if it is yellow and check the finger. If there is no too much blood I will not like to give the baby too much drugs, after sponging with water I will advise the mother to take the baby to the health centre for proper check-up." Another male PMV identified previous home treatment as important in his treatment decision. According to him "I will still ask what they gave the baby before so I will know where I will start with my drugs". Another male respondent mentioned that he would give "Purge tablet like castor oil when the body is very hot and there is no blood, if the purge finish I will now give artesunate"

\section{Parent-Related Factors}

Parent-specific requests and perceived ability to pay elicited during the FGDs were categorized as parent-related factors. A female PMV said "I will also look at whether the mother can pay for the medicine I want to give. If they cannot pay, I will look for a cheaper malarial medicine for them". Another said the child will be referred to the hospital if the parents don't have money. Some PMVs also mentioned that they sometimes offer credit facilities and free drugs to parents if they can't afford the drugs. According to a female PMV, "We don't look at whether they have money or not, sometimes we give for free and sometimes on credit".

Other PMVs mentioned that parent's request for a particular drug was a major factor in their treatment decision. A male PMV said that "some parents ask for $C Q$ and prefer it to ACT because of their experience with the medicine and the price also". Another said that he "will not sell his CQ even when in stock and ACT is out of stock except the parents request for it".

\section{DISCUSSION}

This study explores the malaria treatment practices of PMVs for under-five children based on the National policy on malaria diagnosis and treatment and identifies factors influencing these practices among PMVs in Akwa Ibom State. The PMVs assessed in this study had a mean age of 31.27 years with a majority of them having a secondary education (78.4\%) and about $61 \%$ of them being in practice for 5 years or less. This sociodemographic distribution of PMVs in this study compares similarly with another study done in Lagos. ${ }^{17}$

More than half of the PMVs in this study reported taking at least 5 of the 7 management steps assessed ranging from questions about the child's age, symptoms of illness, duration of illness, previous treatment and explaining drug dosage. 


\section{Original Article}

This was in contrast to findings from previous studies on PMVs in Northern Nigeria and Kenya which reported that PMVs rarely take any form of history before selling medicines for malaria. ${ }^{11,18}$ However, only a few of them $(29.5 \%)$ reported performing any examination like checking the child's temperature, this was also corroborated in the FGDs; this may be because most parents don't usually bring their ill-children to the PMV shop when seeking treatment. ${ }^{11}$

Findings from this study reveal that respondents scarcely gave advice on malaria prevention to clients. This is similar to the findings from other studies in South-Eastern Nigeria and East Africa which had reported that PMVs hardly gave clients advice on prevention. ${ }^{12,19,20}$ This may be because the PMVs are largely profit-oriented, focused on selling their drugs and probably yet to see giving specific advice on malaria prevention as an important part of their service. ${ }^{21}$

In this study, majority of the PMVs reported ACT as the drug they frequently recommended for malaria treatment in children under-five while the rest recommended Chloroquine, SP and other monotherapies. In addition, the antimalarial drug stocking pattern also showed that ACT was stocked by almost all the respondents. These findings generally suggest a positive uptake of the change in antimalarial treatment policy after almost a decade of change in policy from the use of Chloroquine to ACT by the Nigerian Government. ${ }^{5}$

This contrasts with findings from other studies conducted between 2007 and 2009 in Nigeria and East Africa where non-ACT antimalarials (Choloroquine, Sulphadoxinepyrimethamine and Amodiaquine) were the most frequently stocked and recommended antimalarials for children under-five. ${ }^{18,20,21}$ One of the main reasons given by PMVs in previous studies for the poor stocking of ACT was the high market price of the drug which ultimately made it unaffordable to their clients. The wide availability of ACTs in the PMV shops in this study may also be related to its present low retail price of between N100 to N200 as elicited in this study and from a national ACT survey. ${ }^{22}$

This contrasts with the average ACT price of N500 from earlier studies. ${ }^{9}{ }^{23}$ This suggests that the Affordable Medicine for Malaria (AMfM) program made significant progress in its goal of trying to make ACTs widely available and as affordable as the cheapest antimalarial monotherapies. ${ }^{22}$ The continued stocking and sale of Chloroquine, Sulphadoxine/Pyrimethamine and Arthemeter-only therapies by some PMVs was elicited during this study. Findings suggest this practice probably persists because some PMVs consider them relatively cheaper for the clients, with perceived lower side effects and having quick action compared to ACTs.

The practice of polypharmacy by some PMVs was also elicited in this study as was reported in another study in Northern Nigeria. ${ }^{11}$ These inappropriate practices justify the need for continued sensitization and engagement of PMVs by the National Malaria Elimination Program to address and dissuade these practices. This action is important to forestall the development of drug resistance to ACTs as well as the progression to severe illness and possibly death in children treated with non-ACT antimalarials. $^{12}$

This study found that less than $40 \%$ of the PMVs surveyed recommended the appropriate antimalarial drug (ACT) at the right dosage for age. This is similar to findings from other studies in Nigeria as well as Kenya which also assessed the recommended dosage of antimalarial drug administration by PMVs; Chloroquine and Amodiaquine respectively, were the recommended antimalarial drugs of choice at the time. ${ }^{11,18}$ Administering ACT at a sub-optimal dose could lead to possible treatment failure with a worsening prognosis especially in children. This could also contribute to the development and intensification of drug resistance. ${ }^{24}$

This study identified a number of factors to be associated with malaria treatment practices of PMVs. The educational level of PMVs, past attendance of a training on malaria, shop visits by regulatory authorities and the PMVs overall knowledge of malaria including transmission and prevention were significantly associated with recommending the appropriate drug and dosage among the PMVs in this study. These were similarly found to influence malaria treatment by PMVs in other studies in Nigeria and East Africa. ${ }^{25,26}$

The finding from this study that a higher proportion of PMVs with higher educational level recommended appropriate malaria treatment is in agreement with the findings of a study in South-western Nigeria that PMVs with Primary education are less likely to give correct medication. ${ }^{27}$ This finding adds evidence to the need to review the silence on minimal educational qualification for PMVs in the Pharmacy law of Nigeria. In addition, the finding which associated visits by regulatory authorities with appropriate malaria treatment suggests that regulatory visits are vital in helping ensure good standard practice. ${ }^{28}$ The absence of reported regulatory visits by more than $30 \%$ of the respondents in this study was similar to reports from Enugu state. ${ }^{28}$ 
The findings from the FGDs suggest that knowledge of the PMVs plays a very significant role in influencing their treatment practices. Although most PMVs in this study were aware of the policy recommending ACTs as the treatment for malaria, some were unaware the treatment policy discouraged the use of CQ and Artesunate monotherapy in the treatment of malaria in children.

This disposition could also explain the continued stocking and use of these non-ACT antimalarials. A critical appraisal of child illness-related factors reveals that a proper assessment of the severity of illness and decision on treatment is invariably a function of the knowledge of the PMV on malaria presentation and treatment.

Their knowledge therefore influences their actions. The Parent-related factors identified during the focus group discussion bother on parents' request or preference for a particular antimalarial drug based on past experience of efficacy or ability of the parents to pay for the drug. This was found to be a major factor influencing treatment practice by PMVs in a study in Kenya. ${ }^{26,}{ }^{29}$ The sale of non-ACT antimalarial drugs by PMVs that follow client's demand or affordability occurs even when the PMVs know it is an inappropriate drug and might be ineffective. This could be another reason why PMVs continue to stock non-ACT antimalarial drugs in order to satisfy and retain clientele since the PMV's service is primarily a profit-oriented business and is dependent on patronage. ${ }^{20,21}$ This affirms submission from a study in Birnin-Kebbi that factors other than knowledge may be involved in the negative practices of PMVs. ${ }^{30}$ This highlights the need to explore interventions that focus on leveraging on the influence of clients' demand on PMVs malaria treatment practice.

Majority of the respondents in this study reported they would immediately refer a case of severe malaria in children. The proportion of PMVs in the study who recommended referral was higher than findings from studies in South-Eastern Nigeria and Uganda but similar to reports from a study in Tanzania. ${ }^{19,31,32}$ It is however important to note that the reported action of immediate referral for severe malaria by PMVs in the study may be different from their actual practice as elicited during the FGDs. Patent medicine vendors who continue to intensify treatment for severe malaria cases instead of referring are a cause for worry, considering the possible negative consequences of such actions on the children.

Perhaps their drive for profit encourages this action as PMVs vendors have been noted to amplify information on efficacy of medication with the sole aim of increasing sales and profit at the expense of the client. This study found that PMVs who had previously attended a malaria training were more likely to refer severe malaria cases rather than treat. This finding further supports the submission that training can have a significant positive impact on PMV actions and that gaps in knowledge of severe malaria were responsible for poor referral actions by PMVs. ${ }^{8,} 19,21$

This study also found that most of the PMVs were unaware of rectal artesunate for pre-referral treatment and virtually none of them stocked or reported using rectal artesunate.

The WHO recommends pre-referral treatment with rectal artesunate in children with severe malaria and the ease of administration of the medication by non-medically trained persons and the therapeutic effect on parasitemia especially for severe malaria could justify the need for its usage to be encouraged among PMVs. ${ }^{3}$ The prompt referral of severe malaria cases in children to the health facility is vital to reducing childhood mortality due to malaria. With PMVs being the first point of call for treatment in most cases of malaria in children under-five, their actions for severe malaria become undoubtedly very important.

\section{CONCLUSION}

This study shows that ACT is presently the most commonly recommended antimalarial drug for children and is stocked by a majority of PMVs, however, many did not recommend it at the right dose for age. Knowledge on malaria, educational level, previous training on malaria and visits from regulatory bodies were identified as factors associated with recommending the appropriate antimalarial drug, ACT, at the right dosage for age. The knowledge of the PMV, parents' demand and ability to pay and inclination to profiting were underlying influences for the continued stocking and sale of non-ACT antimalarial drugs by the PMVs. The knowledge and practice on management of malaria in children by PMVs can be improved with adequate engagement and training.

\section{ACKNOWLEDGEMENT}

The authors specially acknowledge and honour Late Gen. Simeon E.U. Ekanem who co-tutored and supervised the academic process that produced this work.

\section{REFERENCES}

1. World Health Organization. World Malaria Report 2017. Geneva: World Health Organization. 2017. [cited 2018 Nov 2]. Available from: https://www.who.int/malaria/publications/worldmalaria-report-2017/en/.

2. Federal Ministry of Health. National Malaria Strategic plan 2014-2020. Abuja: Federal Ministry of 
Health; 2014. [cited 2018 Nov 2]. Available from: http://www.nationalplanningcycles.org/sites/default/files/planning_cycle_repository/nigeria/nigeria_national_malaria_strategic_plan.pdf

3. World Health Organization. Guidelines for the treatment of malaria, 2nd Edition. Geneva: World Health Organization; 2010. [cited 2012 Jan 20]. Available from:http://apps.who.int/medicinedocs/documents/s19105en/s19105en.pdf

4. Frosch AE, Venkatesan M, Laufer MK. Patterns of chloroquine use and resistance in sub-Saharan Africa: a systematic review of household survey and molecular data. Malar J. 2011; 10:116.

5. Federal Ministry of Health. National Antimalarial Treatment Policy. Abuja: Federal Ministry of Health; 2005.

6. Onwujekwe O, Dike N, Uzochukwu B. Issues in measuring and improving the treatment of malaria in sub-Saharan Africa. Trop Doct 2005; 35:224-5.

7. Onwujekwe O, Ojukwu J, Uzochukwu B, Dike N, Shu E. Where do people from different socio-economic groups receive diagnosis and treatment for malaria in southeast Nigeria. Ann Trop Med Parasitol. 2005; 99:473-81.

8. Okeke T, Uzochukwu B, Okafor H. An in-depth study of patent medicine sellers' perspectives on malaria in a rural Nigerian community. Malar J 2006; 5:97-104.

9. Oladepo O, Kabiru S, Adeoye B, Oshiname F, Ofi $\mathrm{B}$, Oladepo M, et al. Malaria treatment in Nigeria: the role of patent medicine vendors. United Kingdom: The Future Health Systems, Innovations and knowledge for future health systems for the poor. 2008. [cited 2012 Mar 7]. Available from: http://r4d.dfid.gov.uk/PDF/Outputs/FutureHealth_RPC/WP1.pdf

10. Tobin-West C, Adeniji F. Knowledge and Practices of Patent Medicine Vendors in Rivers State, Nigeria: Implications for Malaria Control in Rural and SubUrban Communities. Indian Journal of Pharmacy Practice. 2012; 5:34-9.

11. Akuse RM, Eseigbe EE, Ahmed A, Brieger W. Patent medicine sellers: How can they help control childhood malaria? Malaria Research and Treatment 2010; 10:4061-68.

12. Goodman C, Brieger W, Unwin A, Mills A, Meek S, Greer G. Medicine sellers and malaria treatment in sub-Saharan Africa: what do they do and how can their practice be improved? The American Journal of Tropical Medicine and Hygiene 2007; 77:203-18.

13. Onwujekwe O, Kaur H, Dike N, Shu E, Uzochukwu B, Hanson K, et al. Quality of anti-malarial drugs provided by public and private healthcare providers in south-east Nigeria. Malar J 2009; 8:22-31.
14. UNFPA. Healthcare services in UNFPA assisted states of Nigeria, Akwa Ibom state report.: UNFPA Nigeria country office. 2010. [cited 2012 Nov 19]. Available from: http://nigeria.unfpa.org/akwaibom.html.

15. AKSG. Akwa Ibom State Government online. Akwa Ibom State Government; [cited 2012 Aug 17]. Available from: http://www.aksgonline.com.

16. Fleiss JT, A; Ury, HK. A simple approximation for calculating sample sizes for comparing independent proportions. Biometrics. 1980; 36:346.

17. Oyeyemi AO, BE; Odukoya, O; Patent Medicine Vendors in Rural Areas of Lagos Nigeria: Compliance with Regulatory Guidelines and Implications for Malaria Control. Tropical Journal of Pharmaceutical Research. 2014; 13: 163-9.

18. Abuya T, Fegan G, Rowa Y, Karisa B, Ochola S, Mutemi W, et al. Impact of ministry of health interventions on private medicine retailer knowledge and practices on anti-malarial treatment in kenya. $\mathrm{Am} \mathrm{J}$ Trop Med Hyg. 2009; 80:905-13.

19. Tawfik Y, Nsungwa-Sabitii J, Greer G, Owor J, Kesande R, Prysor-Jones S. Negotiating improved case management of childhood illness with formal and informal private practitioners in Uganda. Tropical Medicine \& International Health. 2006; 11:96773.

20. Onwujekwe O, Uzochukwu B, Dike N, Uguru N, Nwobi E, Shu E. Malaria treatment perceptions, practices and influences on provider behaviour: comparing hospitals and non-hospitals in south-east Nigeria. Malar J 2009; 8:246-54.

21. Okeke T, Uzochukwu B. Improving childhood malaria treatment and referral practices by training patent medicine vendors in rural south-east Nigeria. Malar J 2009; 8:260-9.

22. ACT Watch. Nigeria Outlet report 2011. [cited 2014 Nov 28]. Available from:

http://www.actwatch.info/countries/nigeria/outletreports/2011.

23. ACT Watch. Nigeria Outlet report 2008. [cited 2014 Nov 28]. Available from:

http://www.actwatch.info/countries/nigeria/outletreports/2008.

24. Yeung S, Pongtavornpinyo W, Hastings I, Mills A, White N. Antimalarial drug resistance, artemisininbased combination therapy, and the contribution of modelling to elucidating policy choices. Am J Trop Med Hyg. 2004; 71: suppl 179-86.

25. Brieger W, Osamor P, Salami K, Oladepo O, Otusanya S. Interactions between patent medicine vendors and customers in urban and rural Nigeria. Health Policy Plan 2004; 19:177-82.

26. Smith N, Obala A, Simiyu C, Menya D, Khwa-Otsyula B, O'Meara W. Accessibility, availability and 
affordability of anti-malarials in a rural district in Kenya after implementation of a national subsidy scheme. Malar J 2011; 10:316-25.

27. Osamor P. Knowledge and selling practice of Patent Medicine Vendors (PMV) regarding the treatment of malaria in Idikan Community, Ibadan, Oyo State. Ibadan: University of Ibadan; 2001.

28. Adikwu M. Sales practices of patent medicine sellers in Nigeria. Health Policy and Planning. 1996; 11:202-5.

29. Tawfik Y, Northrup R, Prysor-Jones S. Utilizing the potential of formal and informal private practitioners in child survival: situation analysis and summary of promising interventions. Support for Analysis and Research in Africa (SARA) Project, Academy for Educational Development; 2002. Washington, DC. [cited 2014 Nov 28] Available from: http://pdf.usaid.gov/pdf_docs/PNACP202.pdf.

30. Livinus $C$, Ibrahim M, Isezuo $S$, Bello $S$. The impact of training on malaria treatment practices: a study of patent medicine vendors in Birnin-kebbi. Sahel Medical Journal 2009; 12:58-64.

31. Greer G, Akinpelumi A, Madueke L, Plowman B, Fapohunda B, Tawfik Y. Improving management of childhood malaria in nigeria and uganda by improving practices of patent medicine vendors. Arlington, Va: BASIC II United States Agency for International Development 2004. [cited 2014 Dec 2]. Available from: https://www.popline.org/node/235674

32. Hetzel M, Dillip A, Lengeler C, Obrist B, Msechu J, Makemba A, et al. Malaria treatment in the retail sector: Knowledge and practices of drug sellers in rural Tanzania. BMC Public Health. 2008; 8:157-68. 